\title{
Impact of land use conversion on soil organic carbon stocks in an agro-pastoral ecotone of Inner Mongolia
}

\author{
ZHAO Wei ${ }^{1,2}$, HU Zhongmin ${ }^{1}$, "LI Shenggong ${ }^{1}$, GUO Qun ${ }^{1}$, YANG Hao ${ }^{1}$, \\ ZHANG Tonghui ${ }^{3}$
}

1. Key Laboratory of Ecosystem Network Observation and Modeling, Institute of Geographic Sciences and Natural Resources Research, CAS, Beijing 100101, China;

2. University of Chinese Academy of Sciences, Beijing 100049, China;

3. Naiman Desertification Research Station, Northwest Institute of Eco-Environment and Resources, CAS, Lanzhou 730000, China

\begin{abstract}
Soil organic carbon (SOC) stocks in terrestrial ecosystems vary considerably with land use types. Grassland, forest, and cropland coexist in the agro-pastoral ecotone of Inner Mongolia, China. Using SOC data compiled from literature and field investigations, this study compared SOC stocks and their vertical distributions among three types of ecosystems. The results indicate that grassland had the largest SOC stock, which was 1.5- and 1.8-folds more than stocks in forest and cropland, respectively. Relative to the stock in $0-100 \mathrm{~cm}$ depth, grassland held more than $40 \%$ of its SOC stock in the upper $20 \mathrm{~cm}$ soil layer; forest and cropland both held over $30 \%$ of their respective SOC stocks in the upper $20 \mathrm{~cm}$ soil layer. SOC stocks in grazed grasslands were remarkably promoted after $\geq 20$ years of grazing exclusion. Conservational cultivation substantially increased the SOC stocks in cropland, especially in the $0-40 \mathrm{~cm}$ depth. Stand ages, tree species, and forest types did not have obvious impacts on forest SOC stocks in the study area likely due to the younger stand ages. Our study implies that soil carbon loss should be taken into account during the implementation of ecological projects, such as reclamation and afforestation, in the arid and semi-arid regions of China.
\end{abstract}

Keywords: soil organic carbon; soil carbon profile; land use change; grazing; tillage; forest age

\section{Introduction}

Soil is the largest carbon sink of global terrestrial biosphere with around $1500 \mathrm{Pg}$ of organic carbon stored in its upper $1 \mathrm{~m}$ depth (Jobbágy and Jackson, 2000), which is 2-3 times the

Received: 2016-08-26 Accepted: 2016-12-09

Foundation: The Strategic Priority Research Program of CAS, No.XDA 05050201; The Funding for Talented Young Scientists of IGSNRR, No.2013 RC203; Youth Innovation Promotion Association of CAS, No.2015037

Author: Zhao Wei (1982-), PhD Candidate, specialized in global carbon cycle and climate change.

E-mail: zhaow.12b@igsnrr.ac.cn

"Corresponding author: Li Shenggong, Professor, specialized in global carbon and water cycle. E-mail: lisg@igsnrr.ac.cn 
carbon pool of vegetation or atmosphere (IPCC, 2007). Soil organic carbon (SOC) is very sensitive to natural and/or human disturbances, leading to negative or positive feedbacks on terrestrial carbon cycle and climate change. As the core of coupled human-environment systems and a potential field in the study of global environmental change (Liu et al., 2010), land use and cover change (LUCC) is the key driver of SOC dynamics (Houghton and Hackler, 2003). LUCC is the second largest source of greenhouse gas emissions, and is responsible for $12.5 \%$ of the human-induced carbon emissions from 1990 to 2010 (Houghton et al., 2012). The gross emission due to tropical land use change reached $1.3 \pm 0.7{\mathrm{Pg} \mathrm{C} \mathrm{yr}^{-1}}^{-1}$ during 1990-2007 (Pan et al., 2011). Ciais et al. (2011) reported that 4 t C ha ${ }^{-1}$ was sequestrated on average in soils due to the conversion of farmland into forest and grassland during 1901-2000 in Europe. Therefore, LUCC-induced soil C dynamics play a major role in terrestrial ecosystem carbon budget in the global climate change context and have been put into the center of scientific research and policy actions as a strategy of the 2015 International Year of Soils (Smith et al., 2015).

The agro-pastoral ecotone located in Inner Mongolia, with an area of $6.5 \times 10^{5} \mathrm{~km}^{2}$ and an arid and semi-arid climate (Zhao et al., 2002), is strongly influenced by various environmental drivers (Ahlstrom et al., 2015) such as water shortage and wind erosion. Its structure, function, and carbon sink-source shift are vulnerable to environmental changes (Midgley et al., 2004). Land degradation and desertification have occurred in the past several decades due to harsh natural conditions, overgrazing, and improper cultivation. In order to cope with environmental degradation and hazardous sand storms, the Chinese government has initiated several ecological restoration projects such as the "Three North Shelter Forest System Project" (1979-2050) and the "Beijing-Tianjin Sandstorm Source Controlling Program" (2000-2010), which have influenced the patterns of land use and land cover in the agro-pastoral ecotone (Wu et al., 2013; He et al., 2015). Grassland, forest and cropland ecosystems coexist and are thus ideal locations to study how land use conversion alters soil C stocks.

Previous studies have investigated SOC stock dynamics in different land use types. Li et al. (2014) found that forests have higher SOC contents than grassland and cropland ecosystems at the $100 \mathrm{~cm}$ depth; however, in the upper $40 \mathrm{~cm}$ depth, grassland ecosystems have higher SOC content than other two systems. Fang et al. (2013) indicated that SOC content in 0-30 cm layer was similar between grazing-excluded grassland and cropland, and both are more than that of free grazing grassland. Xu et al. (2011) showed that SOC stock in 0-50 cm soil layers of grasslands were higher than those in cultivated cropland. However, inconsistent results were drawn on SOC stock change as a result of the sampling soil depth, and management practices (Don et al., 2011; Laganiere et al., 2010; Sun et al., 2016). Therefore, synthetic analyses of SOC stock differences among land use types are imperative to assess soil carbon dynamics and carbon sequestration potential due to LUCC.

In this paper, we compile SOC stock data for 150 sites in the agro-pastoral ecotone in Inner Mongolia of China. These data were obtained from both field investigations and literature surveys. Our main objectives were to (1) compare SOC stocks and their vertical distributions in grassland, forest, and cropland and (2) explore the effects of management measures on the SOC stocks in grassland and cropland, and the effects of stand age, forest type and tree species on the SOC stocks in forest. 


\section{Materials and methods}

\subsection{Study area}

The study area is located in the eastern part of the agro-pastoral ecotone in North China $\left(41.70^{\circ} \mathrm{N}\right.$ to $44.54^{\circ} \mathrm{N}, 115.13^{\circ} \mathrm{E}$ to $\left.122.37^{\circ} \mathrm{E}\right)$. Administratively, it includes Chifeng City, Tongliao City and a part of Xilin Gol League in Inner Mongolia, China (Figure 1). The area has a semi-arid temperate continental monsoon climate. The mean annual temperature ranges between $2.0^{\circ} \mathrm{C}$ and $6.7^{\circ} \mathrm{C}$ and the mean annual precipitation ranges between $320 \mathrm{~mm}$ and $470 \mathrm{~mm}$, over two thirds of which falls in the growing season from May to September. The soils are Kastanozem. The original vegetation is sparse forest grassland, and stems from the Eurasian steppe (Zhao et al., 2002). The major grass species include Leymus chinensis and Stipa baicalensis. The main tree species are Ulmus pumila, Populus simonii, Pinus sylvestris var. mongolica, and Pinus tabulaeformis. The most common crop is Zea mays, accompanied by other crops such as Triticum aestivum and Avena nuda. Grassland, forest and cropland coexist due to frequent human activities such as cultivation, grazing, and the implementation of ecological projects in recent decades. In the agro-pastoral ecotone of Inner Mongolia, vegetation coverage is $29 \%$ for grassland, $9 \%$ for forest, and $8 \%$ for cropland (Zhao et al., 2002).

\subsection{Data compilation}

\subsubsection{Literature survey}

We collected SOC stock data of grasslands, forests and croplands in the

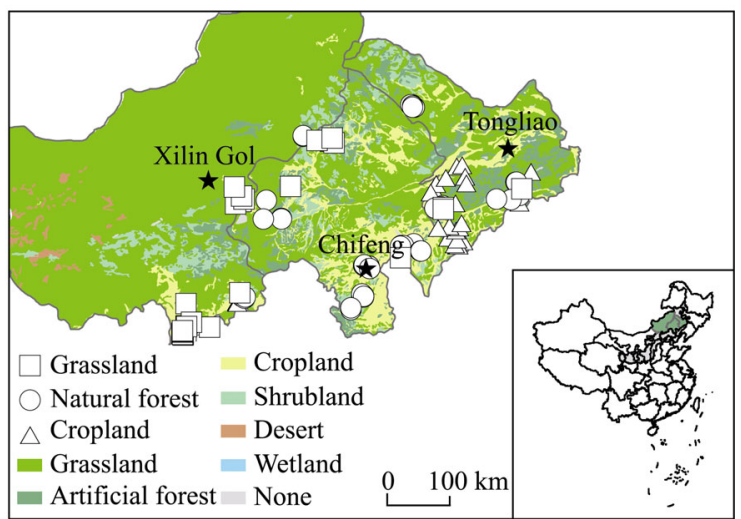

Figure 1 Geographical position of the study area and distribution of sampling sites. This figure was produced using ArcGIS 10.2 (Environmental Systems Research Institute). The background is the vegetation map according to the Editorial Committee of Vegetation Map of China (ECVMC, 2007). study area from literature published between 2000 and 2014 in the Web of Science and China National Knowledge Infrastructure. The soil samples were collected from not less than three depths. When only soil organic matter was available, a factor of 0.58 was used to convert it to SOC (Poeplau et al., 2011). When soil bulk density was not available, the soil bulk density of the closest site was used. The raw data were obtained from tables or extracted from graphs in the papers using the Get Data Graph Digitizer (Version 2.20, Russian Federation). In total, there were 71 grassland sites and 13 cropland sites.

\subsubsection{Field investigation}

Soil samples were collected in 2011 from 0-10, 10-20, 20-30, 30-50 and 50-100 cm depths by digging a hole with a shovel from three quadrats $(1 \mathrm{~m} \times 1 \mathrm{~m})$ in a plot of at least $40 \mathrm{~m} \times$ $40 \mathrm{~m}$ at each cropland site, and from three quadrats $(20 \mathrm{~m} \times 50 \mathrm{~m})$ at each forest site $(>200 \mathrm{~m}$ distance between adjacent sites). Soil bulk density was determined with the core method (using a cylindrical metal $100 \mathrm{~cm}^{3}$ corer) with three replicas at each depth and the soil samples were dried at $65^{\circ} \mathrm{C}$ for more than $24 \mathrm{~h}$ until the weight remained unchanged. SOC con- 
tent was measured using the modified Mebius method (Nelson and Sommers, 1982). Briefly, a $0.5 \mathrm{~g}$ soil sample was digested with $5 \mathrm{ml}$ of $1 \mathrm{~N} \mathrm{~K}_{2} \mathrm{Cr}_{2} \mathrm{O}_{7}$ and $10 \mathrm{ml}$ of concentrated $\mathrm{H}_{2} \mathrm{SO}_{4}$ at $180^{\circ} \mathrm{C}$ for $5 \mathrm{~min}$, followed by titration of the digests with standardized $\mathrm{FeSO}_{4}$. We investigated 23 cropland sites and 43 forest sites.

\subsubsection{Data calculation and analysis}

The SOC stock at each depth (layer) was calculated using Eq. (1):

$$
D_{S O C i}=B D_{i} \times h_{i} \times C_{i} \times 10^{-2},
$$

where $D_{S O C}, B D_{i}$, and $h_{i}$ represent SOC stock $\left(\mathrm{kg} \mathrm{m}^{-2}\right)$, soil bulk density $\left(\mathrm{g} \mathrm{cm}^{-3}\right)$, and thickness (Eclesia et al., 2012) of the $i$ layer (cm), respectively; $C_{i}$ is the SOC content $\left(\mathrm{g} \mathrm{kg}^{-1}\right)$.

Sampling depths for SOC varied in different studies. To compare SOC data collected from different studies and field investigations, the original SOC data were converted to SOC stock in the top $100 \mathrm{~cm}$ depth at each 20 -cm interval using the SOC depth distribution functions developed by Yang et al. (2007). SOC data in the upper three depths from literature survey and in the five depths $(0-100 \mathrm{~cm})$ from field investigation were used to fit Eq. (2). At each 20 -cm interval depth, we obtained the SOC content in volume at $h$ using Eq. (2) and then calculated the SOC stock using Eq. (3) (Yang et al., 2007):

$$
\begin{gathered}
C_{\text {soch }}=a \times \exp ^{b \times h}, \\
D_{\text {soch }}=\int_{h_{1}}^{h_{2}} C_{\text {soch }} d(h) \times 10,
\end{gathered}
$$

where $a$ and $b$ are the coefficients, $h, h_{1}$, and $h_{2}$ are soil depths, and $C_{\text {soch }}$ and $D_{\text {soch }}$ are SOC content in volume $\left(\mathrm{g} \mathrm{cm}^{-3}\right)$ and SOC stock $\left(\mathrm{kg} \mathrm{cm}^{-2}\right)$ at each depth. The SOC stock dataset was compiled with five fixed depths: $0-20,20-40,40-60,60-80$, and 80-100 cm. The coefficient of determination of fit for most SOC sites was above 70\% (all sites for grassland, 36 of 43 sites for forest, and 26 of 36 sites for cropland).

In this study, grasslands were split into grazed (29 sites) and grazing-excluded (GE) (42 sites) sites. The latter was further divided into two groups ( 25 sites for GE<20a and 17 sites for $\mathrm{GE} \geqslant 20 \mathrm{a}$ ) according to the duration for grassland restoration of He et al. (2008). Forests were classified either as natural forest (16 sites) and plantation (27 sites) or as coniferous forest (14 sites) and broad-leaf forest (29 sites). Stand ages of the forests, determined by drilling three tree-ring cores, were grouped into three classes: 0-15a (9 sites), 16-30a (17 sites), and $>30 \mathrm{a}$ (17 sites). Croplands were either under conventional cultivation (tillage) (21 sites) or under conservation cultivation (no-tillage) (15 sites). All statistical analyses were conducted using one-way analysis of variance (ANOVA) with a significance level of 0.05 . ANOVA and correlation analyses were performed using SPSS 16.0 (Chicago, IL, USA).

\section{Results}

\subsection{SOC stocks in different ecosystem types}

On average, SOC stocks in the top $1 \mathrm{~m}$ differed significantly among the three land use types $(p<0.05)$, of which grassland $\left(10.8 \pm 0.87 \mathrm{~kg} \mathrm{~m}^{-2}\right)$ had significantly higher SOC stocks than forest $\left(7.9 \pm 0.89 \mathrm{~kg} \mathrm{~m}^{-2}, p<0.05\right)$ and cropland $\left(6.4 \pm 0.66 \mathrm{~kg} \mathrm{~m}^{-2}, p<0.01\right)$, but forest SOC stocks did not differ significantly from those of cropland $(p=0.296)$ (Figure $2 \mathrm{a})$. In addition, spatial variation in $\mathrm{SOC}$ stocks $(\mathrm{SD}=5.78, C V=73 \%)$ was higher in forest than in grassland 
$(\mathrm{SD}=7.26, C V=67 \%)$ and cropland $(\mathrm{SD}=3.88, C V=60 \%)$.

SOC stocks decreased with depth for each land use type. The difference in SOC stocks between different land use types narrowed with soil depth (Figure $2 b$ ). At the $0-40 \mathrm{~cm}$ depth, grassland SOC stock was significantly higher by $52 \%$ than that of forest $(p<0.05)$; at the 40-100 cm depth, grassland SOC stock was more than that of forest by $13.5 \%$ but was not significantly higher. Compared to cropland, grassland SOC stocks were higher by $79 \%$ $(p<0.05)$ at the $0-60 \mathrm{~cm}$ depth and by $30 \%(p>0.05)$ at the $60-100 \mathrm{~cm}$ depth. Vertical distribution was described by the proportion of SOC content in the $0-20 \mathrm{~cm}$ depth relative to that in 0-100 cm depth (Jobbágy and Jackson, 2000). The vertical distribution patterns of SOC stocks indicate that less SOC is stored in the upper layer of soil $(0-20 \mathrm{~cm})$ in forest (34\%) and cropland (34\%) than in grassland (41\%) in the study area.
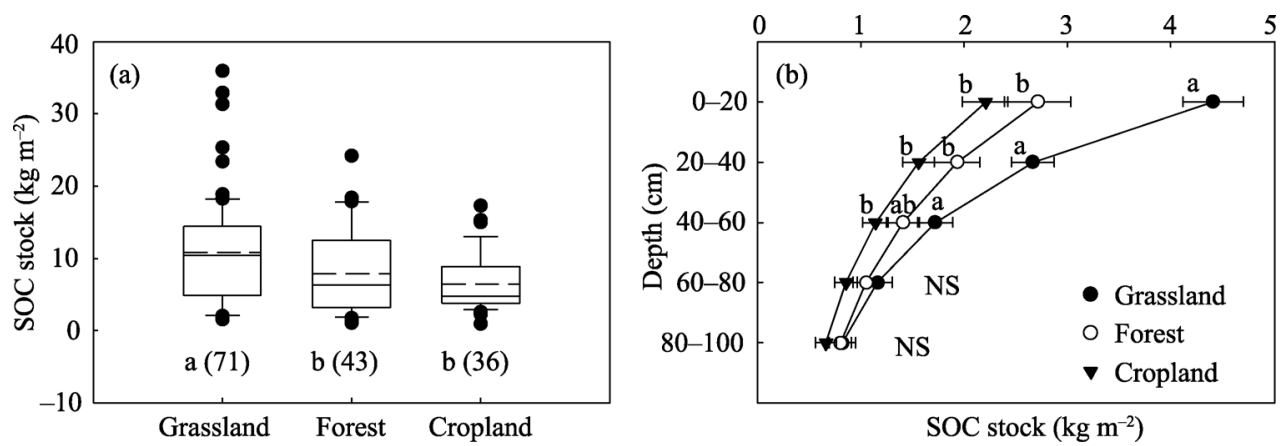

Figure 2 Box plot of soil carbon stocks (a) and their vertical distributions (b) for grassland, forest and cropland. Different letters indicate a significant difference in the total soil carbon stocks and soil carbon stocks of different depths between different land use types at the 0.05 level. NS signifies no significant difference. Bars denote standard error. Values in parentheses indicate the number of samples. Box plots display the median (solid line), mean (dotted line), interquartile range (upper and lower edge of box), 10-90 percentile (whiskers) and outliers (circles).

\subsection{Effects of grazing exclusion on SOC stocks in grassland}

SOC stock was on average $12.2 \mathrm{~kg} \mathrm{~m}^{-2}$ for grazing-excluded (GE) grassland, which is marginally significantly higher than the $8.7 \mathrm{~kg} \mathrm{~m}^{-2}$ for grazed grassland $(p=0.051)$. SOC stocks increased significantly with the duration of GE $\left(R^{2}=0.19, p<0.01\right)$. When the duration of GE was less than 20 years, the SOC stock of GE grassland was $10.5 \mathrm{~kg} \mathrm{~m}^{-2}$, being higher than that of grazing grassland, but not significantly. However, carbon stock $\left(14.7 \mathrm{~kg} \mathrm{~m}^{-2}\right)$ was significantly increased when the duration of GE exceeded 20 years $(p<0.01)$ (Figure $3 a$ ). Such an increase was still observed even when the duration of GE was 30 years, which is the longest GE duration in this dataset.

SOC stock declined with depth for grazed and GE grassland (Figure 3b). At the $0-40 \mathrm{~cm}$ depth, the SOC stock in $\geqslant 20$ a GE grasslands was significantly higher than that in grazed grassland $(p<0.05)$. Throughout the soil profile up to $1 \mathrm{~m}$, no significant difference in SOC stocks was found between the $<20$ year GE grassland and grazed grassland $(p=0.061)$, although slightly higher SOC stocks were observed at each layer in the GE grassland $(<20 \mathrm{a})$ than in grazed grassland (Figure 3b). Larger differences in SOC stocks were detected in the upper layers than in deeper layers among the studied grasslands: e.g., SOC stocks at the $0-20 \mathrm{~cm}$ depth in the $\geqslant 20$ year GE grassland were $71 \%$ and $64 \%$ higher, respectively, than in the $<20$ year GE grassland and grazed grassland, and these percentages declined to $41 \%$ 
and $40 \%$, respectively, at the $20-40 \mathrm{~cm}$ depth (Figure $3 \mathrm{~b}$ ).
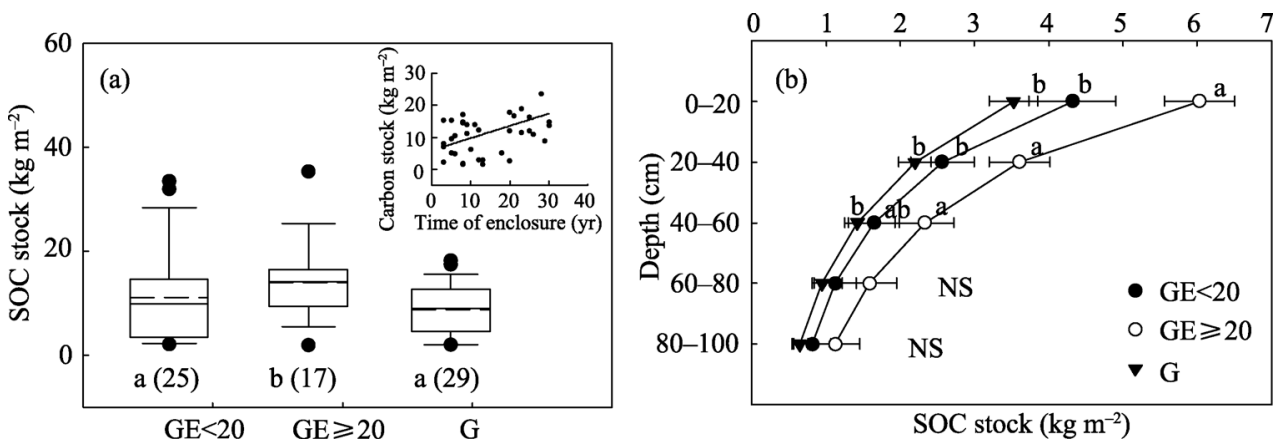

Figure 3 Comparison of SOC stocks (a) and their vertical distributions (b) between grazing-excluded (GE) $(\mathrm{GE}<20 \mathrm{a}, \mathrm{GE} \geqslant 20 \mathrm{a})$ and grazed $(\mathrm{G})$ grasslands. The inset panel shows the relationship between SOC stock and the duration of GE. G, GE $<20$, and GE $\geqslant 20$ represent grazed grasslands, $<20$ years GE, and $\geqslant 20$ years GE grasslands, respectively. Different letters indicate a significant difference $(p<0.05)$ in the total SOC stocks and SOC stocks at different depths among grassland types. Bars denote standard error. NS signifies no significant difference. Values in parentheses indicate the number of samples.

\subsection{Effects of stand age, species identity, and forest type on SOC stocks in forest}

SOC stocks increased evidently but not significantly with forest stand age $(p>0.05)$. The average SOC stocks were $5.2,8.0$, and $9.3 \mathrm{~kg} \mathrm{~m}^{-2}$ in the $0-15,16-30$ and $>30$ year age classes, respectively (Figure $4 \mathrm{a}$ ). Irrespective of tree species, significant linear positive correlations were found between SOC stocks and stand ages for plantations $\left(R^{2}=0.21, p<0.05\right)$, but not for natural forests $(p=0.27)$. Similar to the grasslands, SOC stocks declined with depth, and increased with forest age for each depth (Figure $4 b$ ).
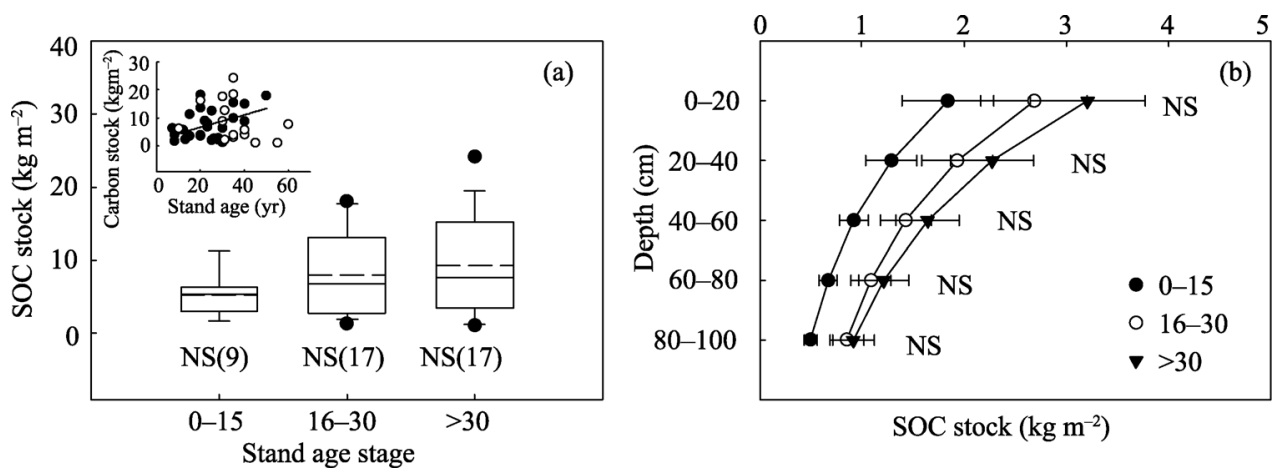

Figure 4 Effects of forest stand age on SOC stocks (a) and their vertical distribution (b). The inset panel in (a) shows the relationship between SOC stocks and forest stand age. Bars denote standard error. NS signifies no significant difference. Values in parentheses indicate the number of samples.

No significant differences in SOC stocks were found between coniferous $\left(8.1 \mathrm{~kg} \mathrm{~m}^{-2}\right)$ and broadleaf forests $\left(7.8 \mathrm{~kg} \mathrm{~m}^{-2}\right)(p=0.90)$ (Figure 5a) and between natural forests $\left(8.7 \mathrm{~kg} \mathrm{~m}^{-2}\right)$ and plantations $\left(7.4 \mathrm{~kg} \mathrm{~m}^{-2}\right)(p=0.50)$ (Figure $\left.5 \mathrm{c}\right)$. Vertical distribution of SOC stocks was similar among the forest types (Figures $5 \mathrm{~b}$ and $5 \mathrm{~d}$ ), but the SOC stock at each depth was slightly higher for natural forests than for plantations (Figure $5 \mathrm{~d}$ ). 

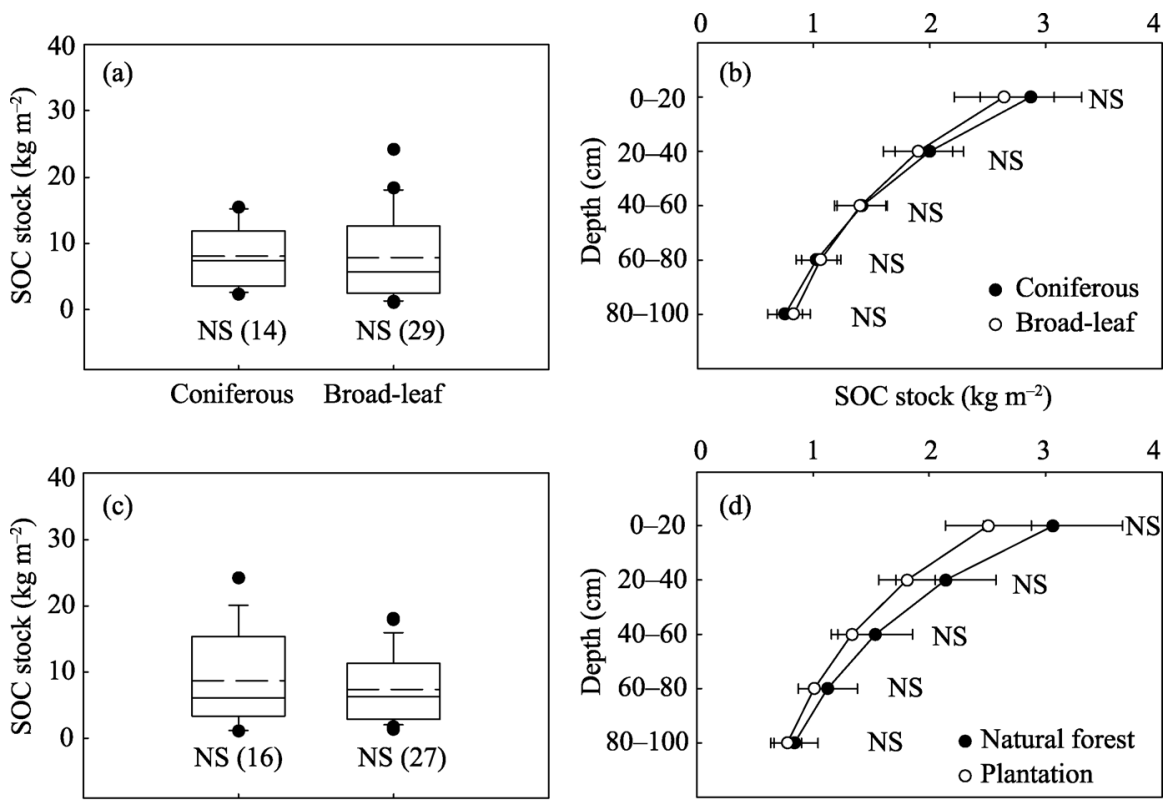

Natural forest Plantation

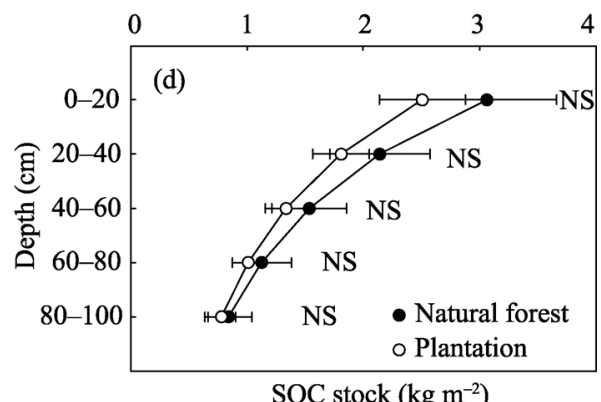

Figure 5 Comparisons of SOC stocks (a, c) and their vertical distribution (b, d) between coniferous and broadleaf forests $(a, b)$ and between natural forests and plantation (c, d). Bars denote standard error. NS signifies no significant difference. Values in parentheses indicate the number of samples.

\subsection{Effects of tillage on SOC stocks in cropland}

In cropland, the SOC stock of conservation cultivated land (no-tillage, $8.4 \mathrm{~kg} \mathrm{~m}^{-2}$ ) was significantly higher than that of conventionally cultivated land (tillage, $\left.5.1 \mathrm{~kg} \mathrm{~m}^{-2}\right)(p<0.05)$ (Figure 6a). On average, no-tillage significantly increased cropland SOC stock by $65 \%$ $\left(3.3 \mathrm{~kg} \mathrm{~m}^{-2}, p<0.05\right)$ compared to tillage (Figure $\left.6 \mathrm{a}\right)$. In terms of vertical distribution, the effect of no-tillage on SOC content largely occurred in the $0-40 \mathrm{~cm}$ depth $(p<0.05)$ (Figure 6b). Compared to tilled croplands, the SOC stocks of no-tillage croplands were greater on average by $1.5,0.9,0.5,0.3$, and $0.2 \mathrm{~kg} \mathrm{~m}^{-2}$ at the $0-20,20-40,40-60,60-80$, and $80-100 \mathrm{~cm}$ depths, respectively. Specifically, the average SOC stocks at the $0-20 \mathrm{~cm}$ and $20-40 \mathrm{~cm}$
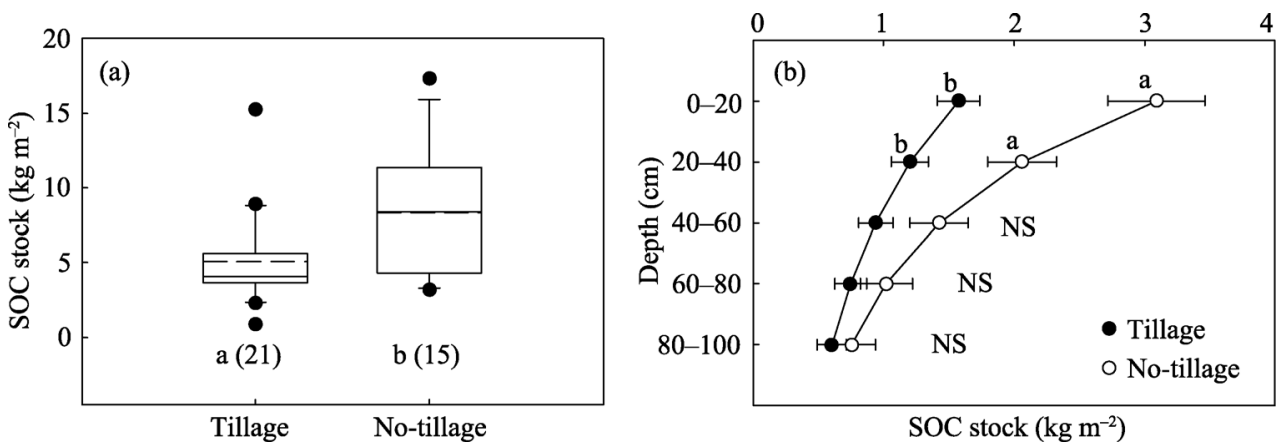

Figure 6 Comparisons of SOC stocks (a) and their vertical distributions (b) between conventional (tillage) and conservation cultivation (no-tillage) croplands. Different letters indicate a significant difference in the SOC stocks of different depths between tillage and no-tillage at the 0.05 level. Bars denote standard error. NS signifies no significant difference. Values in parentheses indicate the number of samples. 
depths were $96 \%$ and $71 \%$ significantly greater, respectively, in the no-tillage croplands than in the tilled croplands $(p<0.05)$.

\section{Discussion}

\subsection{Comparison of SOC stocks among land use types}

Among the three land use types in the agro-pastoral ecotone in Inner Mongolia, grassland exhibited the highest SOC stock, followed by forest and cropland. Grassland that stored more SOC than forest is consistent with the findings of Wei et al. (2012). They reported that grassland ecosystems would have more SOC than planted forests on the Loess Plateau, which is located in a similar climate zone relative to our study area. The higher SOC stock in the grassland compared to the forest is likely ascribed to: (1) low forest stand density leading to less carbon input into the soil from litter; (2) plantations being mainly established on abandoned farmland, which had low SOC stock due to frequent tillage - restoring SOC takes several years to decades. A meta-analysis also shows that, in temperate zones, grassland ecosystems have more SOC than planted forests converted from croplands (Poeplau et al., 2011). Two reasons likely explain the higher SOC stocks in grassland versus cropland systems. Firstly, grassland is not subjected to regular crop harvest (Solomon et al., 2000) and is no-tillage, which increases the biomass inputs and enhances the physical protection of SOC stocks (Post and Kwon, 2000). Secondly, cropland upper soil carbon is easily taken away by the wind, especially during spring, due to surface bareness. Our result is in good agreement with a previous study conducted in the Xilin River Basin of Inner Mongolia that reported the stored total organic carbon in the uppermost $30 \mathrm{~cm}$ soil layer was greater in the grassland than in the cropland (Qi et al., 2012).

Afforestation is supposed to be the plausible pathway to promote terrestrial ecosystem carbon stocks (Lal, 2004; Li et al., 2012); however, in arid and semi-arid regions, the carbon sequestration potential via afforestation is disputable due to water shortage and drought, which have been shown to be unfavorable for forest sustainability and SOC accumulation (Cao, 2008; Cao et al., 2010; Wu et al., 2014). A synthetic analysis shows that the establishment of grassland in temperate zones renders a long lasting carbon sink whereas afforestation of grasslands leads to mostly SOC losses or lack of an SOC sink even after 100 years (Poeplau et al., 2011). This suggests that afforestation or cultivation on original grassland would likely decrease the SOC stock and that grassland restoration would be helpful for increasing SOC stock in semi-arid regions.

In this study, over one third of the SOC was stored in the top $20 \mathrm{~cm}$ depth relative to the total depth studied $(0-100 \mathrm{~cm})$, being higher on average in grasslands $(41 \%)$ than in forests (34\%) and croplands (34\%). This SOC vertical distribution pattern in grassland is similar to that across the world (39\%) (Jobbágy and Jackson, 2000), but is slightly higher than that averaged over China (34\%) (Yang et al., 2007). Although they are located in the same climate zone, the grassland in our study area had a much higher percentage of SOC (41\%) in its 0-20 cm layer than the Loess Plateau (26.8\%) (Wei et al., 2012). This implies that conversion from grassland to other land use types would influence SOC content more remarkably in the upper soil layers than in the deeper soil layers. Deng et al. (2014) also found that land use conversion in China's 'Grain-for-Green' project led to greater SOC changes in up- 
per soil $(0-20 \mathrm{~cm})$ than in deeper soil. Grassland stored more SOC in the $0-20 \mathrm{~cm}$ depth than forest and cropland, and thus would give rise to more SOC loss than the deeper depth when disturbed. Thus, protecting the surface SOC of grassland from destruction plays a major role in ensuring SOC stability in terrestrial ecosystems. This implies that grassland restoration or conversion from croplands and forests to grassland systems may increase SOC sequestration in the agro-pastoral ecotone in Inner Mongolia.

\subsection{Impacts of management on soil organic carbon}

The SOC stock of GE grassland increased by $40 \%$ on average relative to the grazed grassland in this study. Grazing can lower vegetation coverage and reduce carbon input (Dai et al., 2014). GE is considered to be an effective way to improve carbon sequestration (Hu et al., 2015; Pei et al., 2008; Steffens et al., 2008; Su et al., 2005). GE can promote grass growth and biomass accumulation and thereby increase litter-derived carbon input to the soil ( $\mathrm{Hu}$ et al., 2015). Mostly, when vegetation is restored, the avoidance or decrease of wind or water erosion can effectively reduce direct carbon loss from the soil (Hu et al., 2005; Wiesmeier et al., 2015; Zhou et al., 2011). Our study demonstrated that compared to grazed grassland, SOC stocks showed a significant increasing trend for more than 20 years after GE. An obvious increase in SOC stocks was found even after 30 years of GE, the longest GE time in our dataset. However, our result disagrees with the finding of $\mathrm{Hu}$ et al. (2015), who reported that, in North China, the achievement of an SOC stable state takes about 15 years on average after the grassland is fenced against grazing. A major reason for this discrepancy is likely that SOC accumulates slowly in arid and semi-arid regions (Werth et al., 2005) due to droughts. Therefore, more time is required for SOC equilibrium in our study area than in North China. Additionally, in our study, GE grassland is mainly distributed in the agro-pastoral regions, and although fenced, is influenced occasionally by humans or livestock. Further, in a study performed in a region adjacent to our study area, Zhang et al. (2014) suggested that it takes at least 50 years to attain the equilibrium of SOC stock for grasslands recovered from degradation. Lastly, different research scales and grassland types are probable reasons for this discrepancy.

In forests, SOC stocks either in the entire profile up to $100 \mathrm{~cm}$ or in each depth $(20 \mathrm{~cm}$ intervals) was observed to increase with stand age. Globally, there is an overall increasing trend in SOC stocks through time across all biomes (Pregitzer and Euskirchen, 2004). Tree species and forest types did not present obvious impacts on forest SOC stocks probably because most of the forests studied were relatively young. The average stand age was 26 and 31 years for coniferous and broad-leaf forests, and 23 and 39 years for plantation and natural forest.

In cropland, compared with conventional cultivation (tillage), conservational cultivation (no-tillage) increased SOC stock by $65 \%$ and $48 \%$ at $0-100 \mathrm{~cm}$ and $0-20 \mathrm{~cm}$ depths, respectively. Many studies have reported that no-tillage can largely increase SOC stock; tillage disturbs the soil physical aggregate structure, which can increase microbial activity and improve organic matter decomposition (Ogle et al., 2012; Post and Kwon, 2000). However, this increase is primarily limited to the top soil layer (e.g., 0-30 cm) (Ogle et al., 2005; Powlson et al., 2014). The mechanisms of SOC stock increase are not yet fully understood (Ogle et al., 2012). Other than the direct increase in carbon input to the soil through litter 
and/or stubble mulching, the reduction of erosion and runoff and amelioration of water holding capacity might be also important contributors (Palm et al., 2014). Apart from tillage, factors such as crop type, crop rotation, fertilization, and irrigation have direct or indirect effects on SOC dynamics.

\section{Conclusions}

Our results reveal that SOC stocks in grasslands were significantly higher than those of forests and croplands in the agro-pastoral ecotone in Inner Mongolia of China. Compared to forests and croplands, grasslands stored much more SOC in the surface layer, especially in the $0-40 \mathrm{~cm}$ depth. For grasslands and croplands, management practices (e.g., grazing exclusion and tillage) significantly impacted SOC dynamics. The SOC stock of GE grassland was significantly increased after more than 20 years of GE relative to grazing grassland. Conservational cultivation (no-tillage) could improve SOC stocks in croplands, especially in the 0-40 cm soil layer, compared to conventional cultivation (tillage). Our study highlights that in terms of carbon sequestration, reclamation and afforestation should be implemented with caution in arid and semi-arid regions of China.

\section{References}

Ahlstrom A, Raupach M R, Schurgers G et al., 2015. The dominant role of semi-arid ecosystems in the trend and variability of the land $\mathrm{CO}_{2}$ sink. Science, 348(6237): 895-899.

Cao S X, 2008. Why large-scale afforestation efforts in China have failed to solve the desertification problem. Environmental Science \& Technology, 42(20): 1826-1831.

Cao S X, W G S, Chen L, 2010. Questionable value of planting thirsty trees in dry regions. Nature, 465(7294): 31.

Ciais P, Gervois S, Vuichard N et al., 2011. Effects of land use change and management on the European cropland carbon balance. Global Change Biology, 17(1): 320-338.

Dai E F, Zhai R X, Ge Q S et al., 2014. Detecting the storage and change on topsoil organic carbon in grasslands of Inner Mongolia from 1980s to 2010s. Journal of Geographical Sciences, 24(6): 1035-1046.

Deng L, Shangguan Z P, Sweeney S, 2014. "Grain for Green”" driven land use change and carbon sequestration on the Loess Plateau, China. Scientific Reports, 4: 7039.

Don A, Schumacher J, Freibauer A, 2011. Impact of tropical land-use change on soil organic carbon stocks: A meta-analysis. Global Change Biology, 17(4): 1658-1670.

Eclesia R P, Jobbágy E G, Jackson R B et al., 2012. Shifts in soil organic carbon for plantation and pasture establishment in native forests and grasslands of South America. Global Change Biology, 18(10): 3237-3251.

Editorial Committee of Vegetation Map of China (ECVMC), 2007. Vegetation Map of the People's Republic of China (1:1000000). Zhang X S et al. (eds.). Beijing: Geology Publishing House. (in Chinese)

Fang F, Tang H P, Li B Y, 2013. Effects of land use type on soil organic carbon and its fractions. Ecology and Environmental Sciences, 22(11): 1774-1779. (in Chinese)

He B, Chen A F, Wang H L et al., 2015. Dynamic response of satellite-derived vegetation growth to climate change in the Three North Shelter Forest Region in China. Remote Sensing, 7(8): 9998-10016.

He N P, Yu Q, Wu L et al., 2008. Carbon and nitrogen store and storage potential as affected by land-use in a Leymus chinensis grassland of northern China. Soil Biology \& Biochemistry, 40(12): 2952-2959.

Houghton R A, Hackler J L, 2003. Sources and sinks of carbon from land-use change in China, Global Biogeochemical Cycles, 17(2): 1034.

Houghton R A, House J I, Pongratz J et al., 2012. Carbon emissions from land use and land-cover change. Biogeosciences, 9(12): 5125-5142. 
Hu Y F, Liu J Y, Zhuang D F et al., 2005. Distribution characteristics of (CS)-C-137 in wind-eroded soil profile and its use in estimating wind erosion modulus. Chinese Science Bulletin, 50(11): 1155-1159. (in Chinese)

$\mathrm{Hu}$ Z M, Li S G, Guo Q et al., 2016. A synthesis of the effect of grazing exclusion on carbon dynamics in grasslands in China. Global Change Biology, 22(4): 1385-1392.

Intergovernmental Panel of Climate Change (IPCC), 2007. Fourth Assessment Report: Climate Change 2007 (AR4). IPCC, Geneva, Switzerland, 2007.

Jobbágy E G, Jackson R B, 2000. The vertical distribution of soil organic carbon and its relation to climate and vegetation, Ecological Application, 10(2): 423-436.

Laganiere J, Angers D A, Pare D, 2010. Carbon accumulation in agricultural soils after afforestation: A meta-analysis. Global Change Biology, 16(1): 439-453.

Lal R, 2004. Soil carbon sequestration impacts on global climate change and food security. Science, 304(5677): 1623-1627.

Li D J, Niu S L, Luo Y Q, 2012. Global patterns of the dynamics of soil carbon and nitrogen stocks following afforestation: A meta-analysis. New Phytologist, 195(1): 172-181.

Li L, Yao Y F, Qin F C et al., 2014. Spatial variations of organic carbon of Huanghuadianzi watershed in Chifeng. Acta Scientiae Circumstantiae, 34(3): 742-748. (in Chinese)

Liu J Y, Zhang Z X, Xu X L et al., 2010. Spatial patterns and driving forces of land use change in China during the early 21st century. Journal of Geographical Sciences, 20(4): 483-494.

Midgley G F, Aranibar J N, Mantlana K B et al., 2004. Photosynthetic and gas exchange characteristics of dominant woody plants on a moisture gradient in an African savanna. Global Change Biology, 10(3): 309-317.

Nelson D W, Sommers L E, 1982. Total carbon, organic carbon, and organic matter. In: Page A L, Miller R H, Keeney D R eds. Methods of Soil Analysis, Part 2: Chemical and Microbiological Properties. 2nd ed. Madison, WI, USA: ASA and SSSA, 539-579.

Ogle S M, Breidt F J, Paustian K, 2005. Agricultural management impacts on soil organic carbon storage under moist and dry climatic conditions of temperate and tropical regions. Biogeochemistry, 72(1): 87-121.

Ogle S M, Swan A, Paustian K, 2012. No-till management impacts on crop productivity, carbon input and soil carbon sequestration. Agriculture, Ecosystems \& Environment, 149: 37-49.

Palm C, Blanco-Canqui H, DeClerck F et al., 2014. Conservation agriculture and ecosystem services: An overview. Agriculture, Ecosystems \& Environment, 187: 87-105.

Pan Y D, Birdsey R A, Fang J Y et al., 2011. A large and persistent carbon sink in the world's forests. Science, 333(6045): 988-993.

Pei S F, Fu H, Wan C G, 2008. Changes in soil properties and vegetation following exclosure and grazing in degraded Alxa desert steppe of Inner Mongolia, China. Agriculture Ecosystems \& Environment, 124(1): 33-39.

Poeplau C, Don A, Vesterdal L et al., 2011. Temporal dynamics of soil organic carbon after land-use change in the temperate zone: Carbon response functions as a model approach. Global Change Biology, 17(7): 2415-2427.

Post W M, Kwon K C, 2000. Soil carbon sequestration and land-use change: Processes and potential. Global Change Biology, 6(3): 317-327.

Powlson D S, Stirling C M, Jat M L et al., 2014. Limited potential of no-till agriculture for climate change mitigation. Nature Climate Change, 4(8): 678-683.

Pregitzer K S, Euskirchen E S, 2004. Carbon cycling and storage in world forests: biome patterns related to forest age. Global Change Biology, 10(12): 2052-2077.

Qi Y C, Dong Y S, Peng Q et al., 2012. Effects of a conversion from grassland to cropland on the different soil organic carbon fractions in Inner Mongolia, China. Journal of Geographical Sciences, 22(2): 315-328.

Smith P, House J I, Bustamante M et al., 2015. Global change pressures on soils from land use and management. Global Chang Biology, 22(3): 1008-1028.

Solomon D, Lehmann J, Zech W, 2000. Land use effects on soil organic matter properties of chromic luvisols in semi-arid northern Tanzania: Carbon, nitrogen, lignin and carbohydrates. Agriculture Ecosystems \& Environment, 78(3): 203-213.

Steffens M, Kolbl A, Totsche K U et al., 2008. Grazing effects on soil chemical and physical properties in a semi- 
arid steppe of Inner Mongolia (PR China). Geoderma, 143(1/2): 63-72.

Su Y Z, Li Y L, Cui H Y et al., 2005. Influences of continuous grazing and livestock exclusion on soil properties in a degraded sandy grassland, Inner Mongolia, northern China. Catena, 59(3): 267-278.

Sun C L, Xue S, Chai Z Z, 2016. Effects of land-use types on the vertical distribution of fractions of oxidizable organic carbon on the Loess Plateau, China. Journal of Arid Land, 8(2): 221-231.

Wei J, Cheng J M, Li W J et al., 2012. Comparing the effect of naturally restored forest and grassland on carbon sequestration and its vertical distribution in the Chinese Loess Plateau. Plos One, 7(7): e40123.

Werth M, Brauckmann H J, Broll G et al., 2005. Analysis and simulation of soil organic-carbon stocks in grassland ecosystems in SW Germany. Journal of Plant Nutrition and Soil Science, 168(4): 472-482.

Wiesmeier M, Munro S, Barthold F et al., 2015. Carbon storage capacity of semi-arid grassland soils and sequestration potentials in northern China. Global Change Biology, 21(10): 3836-3845.

Wu Z, Wu J, He B et al., 2014. Drought offset ecological restoration program-induced increase in vegetation activity in the Beijing-Tianjin Sand Source Region, China. Environmental Science \& Technology, 48(20): 12108-12117.

$\mathrm{Wu} \mathrm{Z}, \mathrm{Wu} \mathrm{J}$, Liu $\mathrm{J}$ et al., 2013. Increasing terrestrial vegetation activity of ecological restoration program in the Beijing-Tianjin sand source region of China. Ecological Engineering, 52: 37-50.

Xu M Y, L P G, Xie F et al., 2011. Response of soil organic carbon density to land-use types and anagement practices change in agro-pastoral zone. Transactions of the CSAE, 27(7): 320-325. (in Chinese)

Yang Y H, Mohammat A, Feng J M et al., 2007. Storage, patterns and environmental controls of soil organic carbon in China. Biogeochemistry, 84(2): 131-141.

Zhang L X, Fan J W, Zhang W Y et al., 2014. Impact of the Beijing and Tianjin and Source Control Project on the rassland soil organic carbon storage: A case study of Xilingol League, Inner Mongolia, China. Chinese Journal of Applied Ecology, 25(2): 374-380. (in Chinese)

Zhao H L, Zhao X Y, Zhang T H et al., 2002. Boundary line on agro-pasture zigzag zone in North China and its problems on eco-environment. Advance in Earth Sciences, 17(5): 739-747. (in Chinese)

Zhou Z Y, Li F R, Chen S K et al., 2011. Dynamics of vegetation and soil carbon and nitrogen accumulation over 26 years under controlled grazing in a desert shrubland. Plant Soil, 341(1): 257-268. 